\title{
THE STORY OF IOO ACTUARIALLY GUARANTEED NO-RUIN CASUALTY INSURANCE COMPANIES
}

\author{
Hilary L. SEAL \\ Ecole Polytechnique Fédérale de Lausanne \\ "Most people think that an insurance company's \\ business is to make money out of insuring things. \\ They are wrong. Its business is to take as much \\ money off the public as possible, invest it success- \\ fully and hope that the conditions on which it was \\ taken never happen." \\ The Economist, April I3, 1974 (p. I19)
}

\section{Introduction}

In order to motivate the series of Monte Carlo simulations we have carried out in the following article we would like readers to imagine that a small rural casualty insurance company, the Farm Fire and Flood Damage Ins. Co. (FFFDIC), is to be bought by an entrepreneur (whom we shall designate by EP) provided his consulting actuary (the author of this article) can satisfy his requirements which are as follow:

(i) A I5-year investment is foreseen at the end of which time EP wishes to be able to sell, hopefully without loss.

(ii) The risk-capital is to be invested and (although some of it must be in easily liquidable securities) should yield a rate of return comparable with that obtainable on the same amount of capital invested in the market.

(iii) The premiums will not have risk-loadings, as such, but will be loaded for profit by $15 \%$.

(iv) The risk-capital should, on the average, be returnable at the end of the 15 -year investment.

Although EP recognizes that his investment has a certain social utility he must also think in terms of his family, and his age is such that he foresees a need for cash in about 15 years. At that time he wishes to be able to sell his rural insurance company under essen- 
tially the same terms as he bought it; the working capital which he put into the company should still be available and his risk-capital, which actuaries call the risk-reserve, should be essentially intact. This risk-capital will only be used to pay policyholders if EP has a run of bad luck on the claims. It is this circumstance that has caused him to distinguish between the "sure" entities of investment income (item (ii)) and premium loadings (item (iii)), and the "gamble" he is taking with his risk-capital. Since the premiums are not specifically loaded for "risk" the casualty insurance company is playing a "fair" game with its policyholders--if the net premiums have been correctly calculated! EP thus "expects" to "break even" by the end of 15 years but recognizes that long runs of gains or losses do occur (Feller, I968, Ch. III). He has been advised by-his actuary that his risk-capital is really backing for a succession of "even Steven" games.

After some discussion EP and the actuary have agreed that EP should seek a $99 \%$ probability that the risk-capital will not be lost in its entirety and that this probability should be recalculated at the end of each year and the risk-capital adjusted accordingly. Any such release of risk-capital has been called a "capital return" in what follows although we do not recommend that it should be paid out. Instead it should be held against future additional riskcapital requirements which we have called "capital levies".

To summarize then, we have advised EP to separate his "sure" business profits from his "gamble" and to adjust his risk capital every year. We will see that the rural insurance company envisages a constant premium income for the next 15 years and we are proposing to fix the aggregate quarterly premium as our unit of account. This means, of course, that the mean amount of claims in any quarter will also amount to one unit. The aggregate I5-year profit from premium loadings (other than those imposed to meet expenses) will be $15 \%$ of 6 obd or $9 \mathrm{bd}$. (We call the monetary unit the Big Dollar and write it as bd.) The calculations that follow would also apply if, for example, one claim were anticipated every month except that the entrepreneur's investment horizon would then be reduced from 60 quarters to 60 months. 


\section{Loss Distributions, Risk-capitals and Reinsurance}

The consulting actuary has been given the claims experience of the FFFDIC for a fairly long period of years and has concluded that the number of claims has averaged one a quarter and that their number in any quarter is approximated by a mixed Poisson with two components so that the probability of $n$ claims in a quarter is

$$
p_{n}(\mathrm{I})=a_{1} \frac{\alpha_{1}^{n}}{n !} e^{-\alpha_{1}}+a_{2} \frac{\alpha_{2}^{n}}{n !} e^{-\alpha_{2}} \quad n=0, \mathrm{I}, 2, \ldots
$$

where $a_{1}=\mathrm{I}-a_{2}=0.9403, \alpha_{1}=0.7533$ and $\alpha_{2}=4.8547$.

The distribution of individual claim amounts is well represented by a mixed negative exponential with two components so that its probability density may be written

$$
b(x)=b_{1} \beta_{1} e^{-\beta_{1} x}+b_{2} \beta_{2} e^{-\beta_{2} x}
$$

where $b_{1}=\mathrm{I}-b_{2}=0.00663, \beta_{1}=0.09026$ and $\beta_{2}=\mathrm{I} .0722$.

We note that the second moment (about zero) of this distribution is $p_{2}=3.356$ compared with 2.0 for the single exponential with unit mean. By a coincidence the above are the distributions and parameters used by Seal (1974).

Employing the techniques elaborated by Seal in the foregoing reference the consulting actuary has obtained the risk-capitals $w$ that approximately satisfy

$$
U(w, t)=0.99 \quad t=4,8, \ldots 56,60
$$

where $U(w, t)$ is the probability of not losing the whole risk-capital $w$ within $t$ quarters. These values are: $30,42,59,78,97$, II 4 , I3I, $148,165,182,199,216,233,250$, and 267 , respectively. In fact, the actuary computed $U(w, t)$ for $t=\mathrm{I}, 2,3, \ldots 60$ for $w=\mathrm{IO}, 4^{\circ}$ (10) roo (20) 300 with the third decimal figure a unit or so in error (see Seal, 1974) and linearly interpolated for the values of $w$ producing a probability of .990 . The value of $w$ at $t=4$ (namely, 36) looked out-of-line so values of $U(w, t)$ were obtained for $w=26(5) 36$ and $t=\mathrm{I}(\mathrm{I}) 4$, and $w=30$ resulted.

What is interesting about these "target" values of $w$ is that after the first value they increase almost linearly with no sign of "tapering off" by $t=60$. The constant of increase, namely $I 7$, is also very high compared with the Poisson/Exponential case treated by Seal 
(1972). We note that rough interpolation in Seal's Table 3 (loc. cit.) produces a $w$ of 9.4 at $t=4$ and one of 32 at $t=60$ so that the Poisson/Exponential case would have given very poor results if it had been used as a guide to the risk-capital requirements of the FFFDIC.

In fact, EP had complained to his actuary that the initial riskcapital seemed rather high and had asked if it could be reduced. The actuary had previously calculated that if the variance of $b(x)$ were increased fourfold, leaving the mean unchanged at unity and retaining the two-term mixed exponential form $^{3}$ ), the risk-capital at $t=60$ would increase to 285 and this seems a relatively small increase for such a large change in the variance estimate. Nevertheless EP's statement about the initial level of w was the first indication the actuary had had that EP was not "made of money" and he found it incumbent on himself to explain to EP the possibility of "excess loss" reinsurance. For example, if all individual claim amounts in excess of 6 bd were reinsured the initial $w$ would reduce to 213 (see Appendix) but the profit from profit loadings in the premium would reduce to $7.52 \mathrm{bd}$ on the assumption that the whole $15 \%$ was required by the reinsurer (the profit if the reinsurer only required $7.5 \%$-by, for example, having a lower expense loading than the FFFDIC - can easily be seen to be $8.76 \mathrm{bd}$ instead of the $9 \mathrm{bd}$ originally anticipated). Clearly the excess-loss priority can be chosen by a purchaser to conform with his capital availability but the sharply decreasing risk-capital requirements for an investment of limited term should be kept in mind. The important question is: How much can EP afford to lose in a gamble? After some consideration EP decided to risk the whole $267 \mathrm{bd}$.

\section{Ioo Companies like FFFDIC}

The actuary then proceeded to simulate the results of Ioo companies operating under the foregoing "laws" and utilizing the principles laid down by the entrepreneur. The values of $p_{n}(\mathrm{I})$, $n=0, \mathrm{I}, \ldots \mathrm{I} 5$ and of

$$
\int_{x}^{x+1 / 3} b(y) d y \quad x=0, \mathrm{I}, 2, \ldots 39
$$

1) This changed the $\beta^{\prime}$ 's to $\beta_{1}==0.03828 \mathrm{I}$ and $\beta_{2}=\mathrm{J} .201453$, respectively. 
are given in Table I and, with the "tail" modification indicated in the footnote to the table, these were the quantities used in the Monte Carlo runs.

TABLE I

\begin{tabular}{|c|c|c|c|c|c|}
\hline$n$ & ${ }^{\prime} \mathrm{O}^{5} p_{n}(t)$ & $x$ & $\operatorname{IO}^{5} \int_{x}^{x+1 / 3} b(y) d y$ & $x$ & $\operatorname{IO} 0^{5} \int_{x}^{x+1 / 3} b(y) d y$ \\
\hline o & 44228 & o & 2987 I & 20 & 34 \\
\hline I & 33596 & I & 20900 & $2 I$ & 27 \\
\hline 2 & I 3 I 5 I & 2 & 14624 & 22 & 22 \\
\hline 3 & 4060 & 3 & 10235 & 23 & I 8 \\
\hline 4 & 1676 & 4 & 7164 & 24 & $I_{5}$ \\
\hline 5 & I 36 & 5 & 5016 & 25 & I 3 \\
\hline 6 & 857 & 6 & 35 I 3 & 26 & 12 \\
\hline 7 & $5^{88}$ & 7 & 2462 & 27 & I I \\
\hline 8 & 356 & 8 & 1726 & 28 & 10 \\
\hline 9 & I92 & 9 & 1212 & 29 & 9 \\
\hline IO & 93 & IO & $85^{2}$ & $3^{\circ}$ & 9 \\
\hline II & $4 \mathrm{I}$ & I I & 600 & $3 I$ & 8 \\
\hline I2 & I7 & 12 & 423 & 32 & 8 \\
\hline I3 & 6 & 13 & 300 & 33 & 7 \\
\hline I4 & 2 & I 4 & $2 \mathrm{I} 3$ & 34 & 7 \\
\hline \multirow[t]{6}{*}{ I 5} & I & I 5 & I 53 & 35 & 7 \\
\hline & & 16 & IIO & $3^{6}$ & 7 \\
\hline & & I 7 & 80 & 37 & 7 \\
\hline & & I 8 & 59 & $3^{8}$ & 6 \\
\hline & 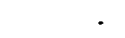 & I9 & 45 & 39 & $205^{*}$ \\
\hline & 100000 & & & & I 00000 \\
\hline
\end{tabular}

*) The complement of the sum of the first 39 probabilities listed.

The pseudo random numbers used were obtained from $\operatorname{RANF}($.$) ,$ the internal random-number function of the CDC 640o. The first of the roo companies was started with a "seed" of 37559 and subsequent companies were started by adding Io times the company number to $37549^{2}$ ). The numbers were used in sets, the first

2) Mr. M. P. Maeder of the University of Lausanne very kindly ran a chisquare test with Ioo classes on the distribution of 4 , ooo numbers commencing with a "seed" of 37559 and obtained a value of 86.20 (with 99.0 "expected"). In similar tests with Io classes on between IO2 and I 46 numbers drawn with "seeds" of $37549+\mathbf{1} 0 i, i=\mathrm{I}, 2,3,4,5$, he obtained chi-square values of I.53, 5.36, 6.04, I 5.78 and 15.21 . respectively, with 9 "expected" in each case. 
TABLE 2

\begin{tabular}{|c|c|c|c|c|c|}
\hline $\begin{array}{l}\text { Company } \\
\text { number }\end{array}$ & $\begin{array}{c}\text { Number } \\
\text { of }= \\
\text { claims }\end{array}$ & $\begin{array}{l}\text { Aggregate } \\
\text { claims }\end{array}$ & $\begin{array}{l}\text { Aggregate } \\
\text { capital } \\
\text { returns }\end{array}$ & $\begin{array}{l}\text { Aggregate } \\
\text { capital } \\
\text { levies }\end{array}$ & $\begin{array}{l}\text { Capital } \\
\text { remaining } \\
\text { at } t=60\end{array}$ \\
\hline I & 86 & 77.67 & 224.00 & & 27.67 \\
\hline 2 & $6 I$ & $4 \mathrm{I} . \mathrm{I} 7$ & $25^{\circ} . \mathrm{I} 7$ & & 32.83 \\
\hline 3 & 42 & 32.33 & 260.00 & & 32.33 \\
\hline 4 & $6 \mathrm{r}$ & 53.83 & 242.17 & & $3^{0} \cdot 5^{\circ}$ \\
\hline 5 & 62 & 58.33 & 247.00 & & 25.83 \\
\hline 6 & $5^{2}$ & 46.00 & $243 \cdot 34$ & & 33.83 \\
\hline 7 & $7^{2}$ & $6 I \cdot 33$ & 244.67 & & 25.50 \\
\hline 8 & 59 & 63.17 & 228.83 & & $3^{2} \cdot 5^{\circ}$ \\
\hline 9 & 63 & 65.50 & 230.16 & & 30.67 \\
\hline IO & 47 & 40.17 & $254 . \mathrm{I} 7$ & & $31 \cdot 33$ \\
\hline I I & 77 & 74.17 & 238.83 & & 22.00 \\
\hline 12 & $5 \mathrm{I}$ & 65.17 & 224.83 & & $33 \cdot 5^{\circ}$ \\
\hline I 3 & $5 \mathrm{I}$ & 69.17 & 226.50 & & 30.67 \\
\hline I 4 & $5^{8}$ & $5^{8.00}$ & 235.66 & & 31.67 \\
\hline I 5 & $4^{2}$ & 39.00 & 260.34 & & 28.83 \\
\hline I 6 & 75 & 64.17 & 230.50 & & 3 I. I 7 \\
\hline I 7 & 47 & $4^{8.17}$ & $247 \cdot 33$ & $0.5^{\circ}$ & 31.00 \\
\hline I 8 & $4 I$ & $4^{0.83}$ & $249.5^{\circ}$ & & $33 \cdot 33$ \\
\hline 19 & 53 & 50.17 & 243.83 & & $3 \mathbf{I} \cdot 5^{\circ}$ \\
\hline 20 & 62 & 66.33 & 230.00 & & 30.33 \\
\hline $2 \mathrm{I}$ & 48 & 61.67 & 230.83 & 0.50 & $32.5^{\circ}$ \\
\hline 22 & 39 & 34.17 & $26 \mathrm{I} . \mathrm{I} 7$ & & 30.83 \\
\hline 23 & 59 & $5^{2} .5^{\circ}$ & 249.50 & & 27.50 \\
\hline 24 & 74 & 66.00 & 224.34 & & $33 \cdot 33$ \\
\hline 25 & 61 & 53.17 & 262.17 & & 20.83 \\
\hline 26 & 39 & $32.5^{\circ}$ & 260.50 & & 32.00 \\
\hline 27 & $4^{\mathrm{I}}$ & $39.5^{\circ}$ & $259.8_{4}$ & & 28.83 \\
\hline 28 & 60 & 64.00 & 226.34 & & $33 \cdot 33$ \\
\hline 29 & 67 & $63.5^{\circ}$ & 228.84 & & 32.33 \\
\hline 30 & $7^{\circ}$ & 64.67 & 229.00 & & 31.67 \\
\hline $3 \mathrm{I}$ & 59 & $4^{8.83}$ & 249.50 & & 29.33 \\
\hline 32 & 83 & $8 \mathrm{I} .50$ & 208.84 & & $33 \cdot 33$ \\
\hline 33 & 55 & $4^{I} \cdot 5^{\circ}$ & $25^{6.50}$ & & $30.5^{\circ}$ \\
\hline 34 & 67 & 78.83 & 221.17 & & $28.5^{\circ}$ \\
\hline 35 & 60 & 56.67 & $233 \cdot 33$ & & 33.50 \\
\hline 36 & $7 \mathrm{I}$ & 70.17 & 219.83 & & $33.5^{\circ}$ \\
\hline 37 & 62 & $55 \cdot 33$ & 247.00 & & $27 \cdot 33$ \\
\hline $3^{8}$ & 56 & 63.00 & 232.34 & & 30.83 \\
\hline 39 & 72 & 64.00 & 238.66 & & 27.17 \\
\hline $4^{\circ}$ & 52 & $\therefore \mathrm{SI} 67$ & 239.33 & & 33.00 \\
\hline $4^{I}$ & 55 & 69.17 & 230.50 & & 28.67 \\
\hline 42 & 63 & $4^{\mathrm{T}} 83$ & 253.83 & & 30.67 \\
\hline 43 & 65 & $75 \cdot 17$ & 224.83 & & $28.5^{\circ}$ \\
\hline 44 & 54 & 57.33 & 234.33 & & 32.67 \\
\hline 45 & $5^{8}$ & $5 \div .67$ & 249.67 & & 27.83 \\
\hline 46 & 54 & 46.00 & 244.00 & & 33.50 \\
\hline 47 & $6 I$ & $4^{6.50}$ & 242.84 & & 33.83 \\
\hline $4^{8}$ & 74 & 73.00 & 218.00 & & 33.00 \\
\hline 49 & 67 & 63.83 & 240.17 & & $26.5^{\circ}$ \\
\hline $5^{\circ}$ & 55 & 66.83 & 226.83 & & 31.67 \\
\hline
\end{tabular}




\begin{tabular}{|c|c|c|c|c|c|}
\hline $\begin{array}{l}\text { Company } \\
\text { number }\end{array}$ & $\begin{array}{c}\text { Number } \\
\text { of } \\
\text { claims }\end{array}$ & $\begin{array}{l}\text { Aggregate } \\
\text { claims }\end{array}$ & $\begin{array}{l}\text { Aggregate } \\
\text { capital } \\
\text { returns }\end{array}$ & $\begin{array}{l}\text { Aggregate } \\
\text { capital } \\
\text { levies }\end{array}$ & $\begin{array}{l}\text { Capital } \\
\text { remaining } \\
\text { at } t=60\end{array}$ \\
\hline 51 & 65 & 74.17 & 219.83 & & $31 \cdot 5^{\circ}$ \\
\hline 52 & $5^{8}$ & 50.33 & 24 I. 67 & & 32.50 \\
\hline 53 & 83 & IOI.I 7 & 196.83 & & $29.5^{\circ}$ \\
\hline 54 & 60 & 60.00 & 229.34 & & 33.83 \\
\hline 55 & 67 & 69.17 & 223.83 & & 32.00 \\
\hline 56 & 60 & $53 \cdot 33$ & 243.67 & & 30.00 \\
\hline 57 & 77 & 79.17 & 212.17 & & 32.83 \\
\hline 58 & $4^{8}$ & $4 \mathrm{I} \cdot 33$ & 249.67 & & 33.00 \\
\hline 59 & 56 & 55.67 & 243.00 & & 29.17 \\
\hline 60 & 73 & 51.83 & 247.17 & & 29,00 \\
\hline 61 & 62 & 84.67 & 204.67 & & 33.83 \\
\hline 62 & 59 & 64.83 & 224.17 & & 34.00 \\
\hline 63 & 60 & $7^{2.00}$ & 217.34 & & 33.83 \\
\hline 64 & 52 & 39.33 & 256.00 & & 30.83 \\
\hline 65 & $7^{2}$ & 66.67 & 226.67 & & $3^{1.83}$ \\
\hline 66 & $5^{8}$ & $5^{8 \cdot 33}$ & 232.00 & & 33.33 \\
\hline 67 & 75 & 72.17 & 237.83 & & $23.5^{\circ}$ \\
\hline 68 & $5^{8}$ & $53 \cdot 33$ & 248.33 & & 27.67 \\
\hline 69 & 59 & $5^{2} \cdot 5^{\circ}$ & 237.84 & & 33.33 \\
\hline 70 & $8 \mathrm{r}$ & 85.17 & $216.5^{\circ}$ & & 27.67 \\
\hline $7 \mathrm{I}$ & 49 & 50.83 & $24 \mathrm{~T} .83$ & & 32.17 \\
\hline 72 & 56 & 60.67 & 231.00 & 0.67 & 33.00 \\
\hline 73 & 49 & $44 \cdot 5^{\circ}$ & 249.16 & & 31.67 \\
\hline 74 & 64 & 58.00 & 246.34 & & 26.33 \\
\hline 75 & $6 \mathrm{I}$ & 66.83 & 236.83 & & 26.67 \\
\hline 76 & 62 & 56.67 & 237.00 & & 31.67 \\
\hline 77 & $5^{6}$ & 69.00 & 231.66 & & 28.17 \\
\hline 78 & 67 & 64.83 & $227.5^{\circ}$ & & 32.33 \\
\hline 79 & 62 & $64 \cdot 33$ & 224.67 & & 34.00 \\
\hline 80 & 53 & 53.17 & 239.17 & & $3^{2} \cdot 33$ \\
\hline $8 \mathrm{I}$ & 64 & 68.00 & 221.66 & & 33.67 \\
\hline 82 & 59 & 47.17 & 241.83 & & 34.00 \\
\hline 83 & 59 & 56.83 & 233.17 & & $33.5^{\circ}$ \\
\hline 84 & 72 & 70.67 & 218.33 & & 34.00 \\
\hline 85 & 62 & $5^{8.33}$ & 237.67 & & $3^{0} .5^{\circ}$ \\
\hline 86 & 59 & $5^{6.17}$ & 233.17 & & 33.83 \\
\hline 87 & 65 & 66.17 & 242.17 & & $24 \cdot 33$ \\
\hline 88 & 60 & 57.67 & $245 \cdot 33$ & & 27.00 \\
\hline 89 & 70 & 73.67 & 220.33 & & 31.50 \\
\hline 90 & 46 & 38.00 & $25 \mathrm{I} \cdot 34$ & & 33.83 \\
\hline $9 I$ & 76 & 77.67 & 224.33 & & 27.50 \\
\hline 92 & $5^{\circ}$ & 61.00 & 239.00 & & $28.5^{\circ}$ \\
\hline 93 & 50 & 47.67 & 246.00 & & 31.67 \\
\hline 94 & 50 & $43 \cdot 33$ & 247.67 & & 33.00 \\
\hline 95 & 49 & 62.17 & 228.17 & & 33.33 \\
\hline 96 & 76 & $77 \cdot 33$ & 234.67 & & $22.5^{\circ}$ \\
\hline 97 & 62 & 46.67 & 259.00 & & 25.67 \\
\hline 98 & $5^{\mathrm{I}}$ & $3^{8.17}$ & 255.83 & & $3^{1} .5^{\circ}$ \\
\hline 99 & 57 & $5^{2.83}$ & 261.83 & & 21.17 \\
\hline IOO & 63 & 55.83 & 240.50 & & 30.33 \\
\hline
\end{tabular}


number of each set indicating the number of claims in the quarter, say $k$, and the $k$ subsequent numbers determining the amounts of the $k$ individual claims; the sum of the $k$ values represented the aggregate claims of the quarter. There were 60 such sets for any one company. The method of transforming the uniform deviates of RANF into numbers drawn from $p_{n}(\mathrm{I})$ or $b(x)$ is by means of the distribution functions of these two distributions (treating the latter as a "discrete" distribution as indicated in Table I) and is described by, e.g., Hammersley \& Handscomb (1964, Sec. 3.4).

The simulated risk-capital at the end of each quarter was obtained from that of the previous quarter by adding I (unit premium) and by subtracting the simulated aggregate claims of the quarter. The starting risk-capital was 267 , as already indicated, and the resulting risk-capital at the end of four quarters was replaced by 250 with a consequent release of capital. This procedure was continued for the 6o quarters, the last capital replacement being at the end of $5^{6}$ quarters with a value of 30 . A summary of the results for the Ioo companies is given in Table 2 . We note that the aggregate net capital returns of any company added to the capital remaining at the end of the 15 years is to be compared with the initial 267 invested in the company. We may call any surplus thus obtained a "gambling profit" and the actual values are shown in the "without inflation" columns of Table 4.

TABLE 3

\begin{tabular}{|c|c|c|c|c|}
\hline \multicolumn{2}{|c|}{$\frac{x-60}{\sigma}$} & \multirow{2}{*}{$\begin{array}{c}\begin{array}{c}\text { Normal } \\
\text { curve }\end{array} \\
2.2\end{array}$} & \multirow{2}{*}{$\begin{array}{c}\begin{array}{c}\text { Number of } \\
\text { claims }\end{array} \\
-\end{array}$} & \multirow{2}{*}{$\begin{array}{c}\begin{array}{c}\text { Aggregate } \\
\text { claims }\end{array} \\
-\end{array}$} \\
\hline$(-3)$ & $-(-2)$ & & & \\
\hline$(-2)$ & $-(-\mathbf{I})$ & 13.6 & 15 & I 5 \\
\hline$(-\mathbf{I})$ & $-\quad 0$ & 34.1 & 39 & 38 \\
\hline o & - & 34.1 & 28 & 38 \\
\hline $\mathbf{I}$ & - & I 3.6 & I5 & 8 \\
\hline \multirow{2}{*}{\multicolumn{2}{|c|}{$2-$}} & 2.2 & 3 & I \\
\hline & & 99.8 & 100 & 100 \\
\hline
\end{tabular}

$\boldsymbol{x}=$ number of claims, or aggregate claims, in 15 years

$\sigma=10.7982$ when $x=$ number of claims

$=\mathrm{I} 6.0609$ when $x=$ aggregate claims 
TABLE 4

\begin{tabular}{|c|c|c|}
\hline \multirow[b]{2}{*}{$\begin{array}{l}\text { Company } \\
\text { number }\end{array}$} & \multicolumn{2}{|c|}{ Gambling Profit } \\
\hline & $\begin{array}{l}\text { Without } \\
\text { inflation }\end{array}$ & $\begin{array}{l}\text { With } \\
\text { inflation }\end{array}$ \\
\hline I & - I 5.33 & -33.44 \\
\hline 2 & 16.00 & $24 \cdot 32$ \\
\hline 3 & $25 \cdot 33$ & 38.35 \\
\hline 4 & 5.67 & $13.7 \mathrm{I}$ \\
\hline 5 & 5.83 & $7.6 \mathrm{I}$ \\
\hline 6 & 10.17 & 18.19 \\
\hline $\begin{array}{l}7 \\
8\end{array}$ & $\begin{array}{r}3.17 \\
-\quad 5.67\end{array}$ & $\begin{array}{r}8.20 \\
-\mathrm{I} 8.48\end{array}$ \\
\hline 9 & -6.17 & $\begin{array}{l}-10.40 \\
-10.20\end{array}$ \\
\hline IO & $18.5^{\circ}$ & 26.85 \\
\hline II & -6.17 & $-\mathrm{I} 6.16$ \\
\hline I 2 & -8.67 & -0.60 \\
\hline I3 & -9.83 & $-22.8 \mathrm{I}$ \\
\hline 14 & 0.33 & 2.53 \\
\hline 15 & 22.17 & 34.18 \\
\hline I6 & -5.33 & -Io.86 \\
\hline I7 & 10.83 & 3.29 \\
\hline 18 & 15.83 & $29 \cdot 33$ \\
\hline 19 & 8.33 & I0.4 I \\
\hline 20 & -6.67 & $-6.7 \mathrm{I}$ \\
\hline 21 & -4.17 & —I0.57 \\
\hline 22 & 25.00 & $35 \cdot 5^{8}$ \\
\hline 23 & 10.00 & $25 \cdot 34$ \\
\hline 24 & $-9 \cdot 33$ & - I 7.68 \\
\hline 25 & I6.00 & 22.00 \\
\hline 26 & $25 \cdot 5^{\circ}$ & $39 \cdot 5^{2}$ \\
\hline 27 & 21.67 & 32.44 \\
\hline 28 & $-7 \cdot 33$ & $-\mathrm{I} 4.34$ \\
\hline 29 & -5.83 & -12.26 \\
\hline 30 & -6.33 & -0.79 \\
\hline $3 I$ & I I. 83 & II. 40 \\
\hline 32 & -24.83 & -35.99 \\
\hline 33 & I 8.00 & $27.4^{\circ}$ \\
\hline 34 & -17.33 & -30.14 \\
\hline 35 & -0.17 & -2.08 \\
\hline $3^{6}$ & $-\mathbf{I} 3.67$ & -25.25 \\
\hline 37 & $7 \cdot 33$ & 16.29 \\
\hline 38 & -3.83 & 4.24 \\
\hline 39 & - I.17 & $-3.4^{2}$ \\
\hline $4^{\circ}$ & $5 \cdot 33$ & 12.93 \\
\hline $4 \mathrm{I}$ & -7.83 & -I 3.54 \\
\hline 42 & $17.5^{\circ}$ & $27 \cdot 38$ \\
\hline 43 & $-\mathrm{I} 3.67$ & $-\mathrm{I} 7.75$ \\
\hline 44 & 0.00 & 4.62 \\
\hline 45 & 10.50 & $23.9 \mathrm{I}$ \\
\hline 46 & $10.5^{\circ}$ & $6.6 \mathrm{I}$ \\
\hline 47 & 9.67 & 4.84 \\
\hline $\begin{array}{l}48 \\
49\end{array}$ & $\begin{array}{r}\text { - } 16.00 \\
-0.33\end{array}$ & $\begin{array}{r}-23.62 \\
-4.53\end{array}$ \\
\hline
\end{tabular}




\begin{tabular}{|c|c|c|}
\hline \multirow[b]{2}{*}{$\begin{array}{l}\text { Company } \\
\text { number }\end{array}$} & \multicolumn{2}{|c|}{ Gambling Profit } \\
\hline & $\begin{array}{l}\text { Without } \\
\text { inflation }\end{array}$ & $\begin{array}{c}\text { With } \\
\text { inflation }\end{array}$ \\
\hline $5 I$ & $-\mathbf{I} 5.67$ & $-2 \mathrm{I} .8 \mathrm{I}$ \\
\hline $5^{2}$ & $7 \cdot 17$ & 12.33 \\
\hline 53 & -40.67 & $-57 \cdot 4^{6}$ \\
\hline 54 & -3.83 & $-2.3^{2}$ \\
\hline 55 & 一II.I 7 & -26.14 \\
\hline 56 & 6.67 & 12.80 \\
\hline 57 & -22.00 & $-45.5 \mathrm{I}$ \\
\hline $5^{8}$ & I 5.67 & I 4.67 \\
\hline 59 & 5.17 & 16.56 \\
\hline 60 & 9.17 & I 4.54 \\
\hline 61 & $-28.5^{\circ}$ & -52.15 \\
\hline 62 & -8.83 & $-\mathrm{I}_{4} .9 \mathrm{I}$ \\
\hline 63 & $-\mathrm{I}_{5} .83$ & -23.83 \\
\hline 64 & I 9.83 & $28.4^{8}$ \\
\hline 65 & $-8.5^{\circ}$ & $-\mathbf{I} 5.99$ \\
\hline 66 & $-\mathbf{1 . 6 7}$ & 6.99 \\
\hline 67 & -5.67 & 0.10 \\
\hline 68 & 9.00 & 6.97 \\
\hline 69 & 4.I 7 & 3.I 4 \\
\hline 70 & -22.83 & -36.49 \\
\hline 71 & 7.00 & I 5.32 \\
\hline $7^{2}$ & -3.67 & -I6.44 \\
\hline 73 & I 3.83 & I 8.06 \\
\hline 74 & 5.67 & 8.62 \\
\hline 75 & $-3.5^{\circ}$ & $-7 \cdot 37$ \\
\hline 76 & I. 67 & -0.32 \\
\hline 77 & -7.17 & $-\mathrm{I} 4.30$ \\
\hline 78 & -7.17 & $-6.3^{8}$ \\
\hline 79 & -8.33 & -3.08 \\
\hline 80 & $4 \cdot 5^{\circ}$ & $5.6 \mathrm{I}$ \\
\hline $8 \mathrm{I}$ & $-1 \mathrm{I} .67$ & -20.33 \\
\hline 82 & 8.83 & I8.96 \\
\hline 83 & -0.33 & $-8.2 \mathrm{I}$ \\
\hline 84 & $-\mathrm{I} 4.67$ & $-\mathrm{I} 2.43$ \\
\hline 85 & I.I 7 & $3 \cdot 17$ \\
\hline 86 & 0.00 & -II.66 \\
\hline 87 & -0.50 & -2.54 \\
\hline 88 & $5 \cdot 33$ & 12.24 \\
\hline 89 & $-\mathrm{I} 5.17$ & -26.14 \\
\hline 90 & I8. 7 & 23.93 \\
\hline $9 \mathrm{I}$ & -15.17 & -32.98 \\
\hline 92 & $0.5^{\circ}$ & $-\mathbf{I} 0.80$ \\
\hline 93 & 10.67 & 13.33 \\
\hline 94 & 13.67 & $10.5^{I}$ \\
\hline 95 & $-5.5^{\circ}$ & -8.02 \\
\hline 96 & -9.83 & -29.46 \\
\hline 97 & I 7.67 & 20.87 \\
\hline 98 & 20.33 & 33.17 \\
\hline 99 & 16.00 & $19.5^{\circ}$ \\
\hline 100 & 3.83 & I. 34 \\
\hline
\end{tabular}


The variance of the number of claims in any quarter can be shown to be

$$
\alpha_{1}^{2}\left(a_{1}-a_{1}^{2}\right)+\alpha_{2}^{2}\left(a_{2}-a_{2}^{2}\right)+\mathrm{I}-2 a_{1} a_{2} \alpha_{1} \alpha_{2}=\mathrm{I} .94337
$$

(compared with I.o for the simple Poisson). And the variance of one quarter's aggregate amount of claims is

$$
\sigma^{2}=p_{2}+a_{1} \alpha_{1}^{2}+a_{2} \alpha_{2}^{2}--\mathrm{I}=4.29924
$$

(compared with 2.0 for the Poisson/Exponential case). On multiplying these results by 60 and taking the square roots one can make the foregoing (Table 3 ) rough comparisons of the claim numbers and amounts of Table 2 with the Normal curve. The agreement is satisfactory although one can say that the Ioo companies were "lucky" in that an excessive aggregate amount of claims never occurred. (One wonders if the collapse of the tail of $b(\cdot)$ in Table I had anything to do with this.)

In Table 4 the largest I5-year "gambling profit" (without inflation) is seen to be $25.5^{\circ}$ (company no. 26) and the greatest loss 40.67 (company no. 53). One half the companies had profits over the 15-year span. These are agreeably reassuring results: not a single one of the Ioo companies required more capital than EP had supplied, and in the worst case EP only lost $15 \%$ of his $267 \mathrm{bd}$ of gambling capital. This is not to say that some EP, somewhere, will not lose the whole of his $267 \mathrm{bd}$ when doing business under similar circumstances.

\section{Operation in a Strungly Inflationary Era}

What would have happened to the foregoing Ioo companies if there had been a consistent inflation of $\mathbf{I} .5 \%$ per quarter? In other words, suppose the amount of claims in quarter $t(t=\mathrm{I}, 2,3, \ldots 60)$ had been multiplied by (I.OI5) ${ }^{t-1}$ how would the companies' profits have turned out?

In general the actuary must be prepared for an upward shift in the mean of the distribution of aggregate claims and must adjust his premiums upwards if it occurs. Such an upward shift could be identified by the routine application of a standard "Cusum" 
technique (Bruyn, I968). Specifically the actuary would calculate every quarter (in this case)

$$
\begin{array}{r}
S_{t}=\max \left(0, S_{t-1}+\frac{\text { claims in quarter } t-\text { net premium }}{\sigma}-\frac{g}{2}\right), \\
S_{0}=0
\end{array}
$$

and a premium increase would be required every time $S_{t}>3$. Broadly, this implies unjustified signals for an increase once in every 20 quarters, and an average run length of $6 / g^{2}$ if the mean of the quarterly claim amounts has shifted upwards by g $\sigma$ (loc. cit.). The choice of a reasonable value for $g$ is, however, extraordinarily difficult. For example, if $g=\mathrm{I}$ an average run length of 6 is required to detect a bias of $\sigma=2.07$ but, since the initial premium is unity, this is absurdly inefficient. The reason is, of course, the size of $\sigma$ in comparison with the unit mean. It explains, perhaps, why actuaries have imposed premium increases long before they were really justified!

However in the case of persistent inflation no statistical tests of claim trend are needed. Instead, an estimate of the rate of inflation is required and has to be applied to the premium scale. (Exactly how the company should apply a relatively small quarterly increase is a practical matter which depends upon competition.) We assume that every quarterly premium is I.OI5 times the premium of the previous quarter. Similarly the target $w$-values calculated on the basis of no inflationary (or other) trend were multiplied by the concurrent net premium values. The resulting "gambling profits" of the roo companies are given in Table 4 .

A comparison of the two sets of gambling losses in Table 4, without and with inflation, shows considerable correlation, as might be expected since the basic numbers and pre-inflation amounts of claims are the same, company by company. Thus the "luckiest" and "unluckiest" companies are the same in both cases (nos. 26 and 53, respectively) but, in general, the profits and losses are absolutely larger in the inflationary situation. Nevertheless the relative smallness of the gambling profits remains unchanged in the case of inflation. The entrepreneur must expect greater losses-and profits-when his actuary has correctly estimated an upward 
premium trend but these are far less than the "total loss" of $267 \mathrm{bd}$ that could occur under very unfavorable chance circumstances.

\section{APPENDIX}

\section{Excess-loss Reinsurance of a Mixed Exponential}

Suppose that the probability density of individual claim amounts is

$$
b(x)=b_{1} \beta_{1} e^{-\beta_{1} x}+b_{2} \beta_{2} e^{-\beta_{2} x} \quad 0<x<\infty
$$

where $b_{1}+b_{2}=\mathrm{I}$ and $\frac{b_{1}}{\beta_{1}}+\frac{b_{2}}{\beta_{2}}=\mathbf{I}$, and that an excess-loss reinsurance contract has been effected at priority $p$. Then the probability density of unreinsured individual claim amounts is $c(x)=\left[\mathrm{I}-b_{1} e^{-\beta_{1} p}-b_{2} e^{-\beta_{2} p}\right]^{-1}\left[b_{1} \beta_{1} e^{-\beta_{1} x}+b_{2} \beta_{2} e^{-\beta_{2} x}\right] \quad 0<x<p$

The first of the two factors in this expression is the proportion of the distribution retained by the principal insurer and with $p=6$ and the $b$ 's and $\beta$ 's those of the foregoing article this proportion is 0.99400 . Put $z=h x$ and the probability density of $z$ is

$$
g(z)=(\mathrm{I} / h) c(z / h) \quad 0<z<h p
$$

In order to make the mean of this latter distribution equal to unity we have to determine $h$ so that

$$
\begin{gathered}
\mathrm{I}=\int_{0}^{h p} z g(z) d z \\
=(\mathrm{I} / h)\left[\mathrm{I}-b_{1} e^{-\beta_{1} p}-b_{2} e^{-\beta_{2} p}\right]^{-1}\left[b_{1} \beta_{1} \int_{0}^{h p} z e^{-\beta_{1} z / h} d z+b_{2} \beta_{2} \int_{0}^{h p} z^{-\beta_{2} z / h} d z\right] \\
\text { or } \\
\qquad \begin{array}{c}
h^{-1}=\left[\mathrm{I}-b_{1} e^{-\beta_{1} p}-b_{2} e^{-\beta_{2} p}\right]^{-1}\left[b_{1}\left(\frac{\mathrm{I}-e^{-\beta_{1} p}}{\beta_{1}}-p e^{-\beta_{1} p}\right)+\right. \\
\left.+b_{2}\left(\frac{\mathrm{I}-e^{-\beta_{2} p}}{\beta_{2}}-p e^{-\beta_{2} p}\right)\right]
\end{array}
\end{gathered}
$$

We observe that the Laplace Transform of $g(\cdot)$ is

$$
\begin{gathered}
\gamma(s)=\int_{0}^{h p} e^{-z s} g(z) d z=\int_{0}^{p} e^{-u h s} c(u) d u \\
=\left[\mathrm{I}-b_{1} e^{-\beta_{1} p}-b_{2} e^{-\beta_{2} p}\right]^{-1}\left[b_{1} \beta_{1} \frac{\mathrm{I}-e^{-\left(s h+\beta_{1}\right) p}}{s h+\beta_{1}}+b_{2} \beta_{2} \frac{\mathrm{I}-e^{-\left(s h+\beta_{2}\right) p}}{s h+\beta_{2}}\right]
\end{gathered}
$$


Note that in the original monetary units the mean of the retained individual claim amounts is

$$
\begin{aligned}
\int_{0}^{p} x b(x) d x & =b_{1}\left[\frac{\mathrm{I}-e^{-\beta_{1} p}}{\beta_{1}}-p e^{-\beta_{1} p}\right]+b_{2}\left[\frac{\mathrm{I}-e^{-\beta_{2} p}}{\beta_{2}}-p e^{-\beta_{2} p}\right] \\
& =.8357 \mathrm{I} \text { in the illustrative case. }
\end{aligned}
$$

Using the above Laplace Transform and the parameters of the foregoing article we calculated $U(w, t), w=260(\mathrm{I}) 280, t=$ I (I) 60 and, on linear extrapolation obtained $U(255,60)=.990$. In the original Big Dollar units tha risk-capital required by the principal insurer is thus $255 \times .8357 \mathrm{I}=2 \mathrm{I} 3$.

\section{REFERENCES}

Bruyn, C. S. Van D. (1968). Cumulative Sum Tests: Theory and Practice. Griffin, London.

Feller, W. (1968). An Introduction to Probability Theory and Its Applications. Wiley, New York.

Hammersley, J. M. \& D. C. Handscomb (1964). Monte Carlo Method's. Methuen, London.

SEAL, H. L. (1972). "Numerical calculation of the probability of ruin in the Poisson/Exponential case." Mitt. Verein. schweiz. Versich.-Mathr., 72, 77-100.

-_. (1974). "The numerical calculation of $U(w, t)$, the probability of nonruin in an interval $(\mathrm{o}, \mathrm{t})$. ." Scand. Actu. J., I974, No. 3, I2 I-I39. 